\title{
Military Workforce Analytics
}

\author{
Michelle C. Straver
}

\section{Contents}

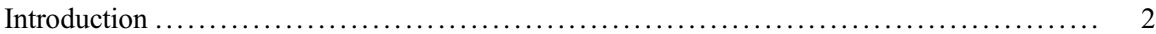

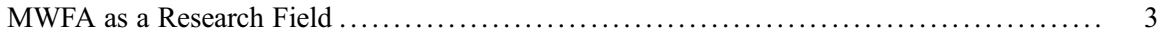

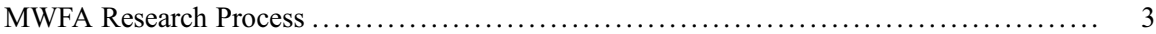

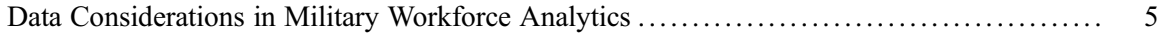

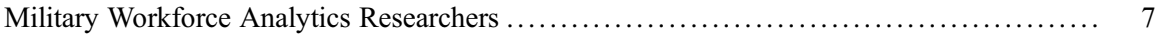

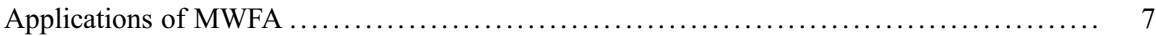

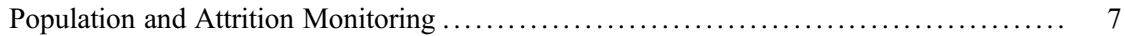

Attrition Analysis ....................................................... 8

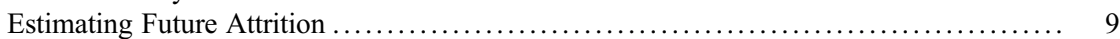

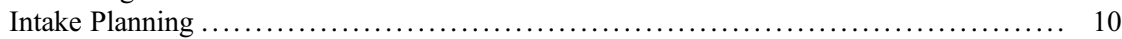

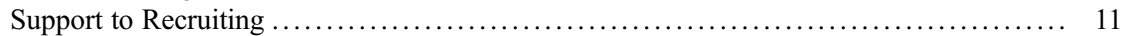

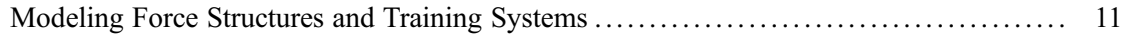

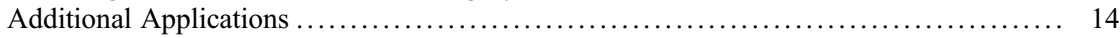

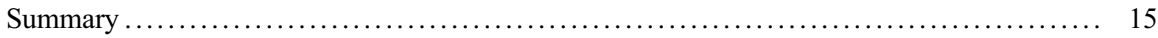

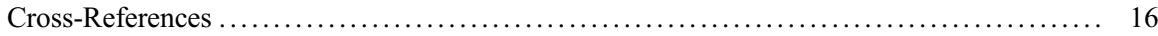

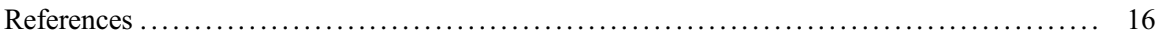

\section{Abstract}

As a consequence of the closed, hierarchical nature of military organizations, good planning is key to ensuring that a military workforce will be well-situated to meet future demands. This chapter explores the role of data-driven decision support (referred to as analytics) in military workforce planning. As an applied research field, analytics aims to provide actionable insights and practical solutions to questions posed by decision-makers. Since data underlie all analytics, this chapter touches on the challenges of data-related issues such as accessibility, integration, and completeness, highlighting the importance of understanding the

M. C. Straver ( $\triangle)$

Director General Military Personnel Research and Analysis, Department of National Defence, Ottawa, Canada

e-mail: michelle.straver@forces.gc.ca

(C) The Author(s) 2021 https://doi.org/10.1007/978-3-030-02866-4_84-1 
data and the context around it. Next, several areas where analytics are used to solve military workforce planning problems are discussed. This will give the reader a sense of the breadth of the domain, as well as the various approaches that can be employed by a practitioner.

\section{Keywords}

Workforce planning · Analytics · Operational research · Modeling · Simulation · Recruiting $\cdot$ Attrition $\cdot$ Training system $\cdot$ Force structure

\section{Introduction}

How many military members need to be recruited to meet future staffing requirements? How many women and members of different ethnic groups need to be recruited to meet diversity goals? Do members who join the military through subsidized education programs remain longer than their direct entry counterparts? Are attrition rates of military members increasing; and if so, are some groups affected more than others? Which military occupations are consistently understaffed, and what can be done to improve the situation? Are there bottlenecks in the training system that need to be addressed?

Unlike civilian organizations, military organizations have a closed, hierarchical nature, meaning that members join the military at the lowest rank and work their way up through the ranks over time as they gain skills and experience, until they are eventually released. This poses unique staffing challenges, and as such, even more so than other types of organizations, military establishments must understand their workforces in order to be able to continually meet their staffing requirements. Decisions made today can have long-term consequences.

Analytics can help to answer the above questions. Defined broadly, analytics refers to scientific means of using data and analysis methods to support decision-making, including the fields of data science, statistics, operational research, computer science, etc. These approaches have been used for decades for solving workforce planning problems; and while methods that have been used for many years remain useful today (most notably in the area of operational research), there is also potential to use emerging technologies to enable new insights. At the same time, military organizations are increasingly recognizing the importance of these capabilities, encouraging the use of data-driven decision support and seeking to take advantage of advancements in the field, which has come to be known as military workforce analytics (MWFA).

The remainder of this chapter begins by discussing the concept of MWFA as a research field, and an overview of the research process is given. Next, data considerations are discussed, with the aim of illustrating some of the challenges faced by MWFA practitioners. Finally, some common applications and methods are presented. 


\section{MWFA as a Research Field}

As an applied research field, analytics aims to support decision-making by providing useful insights and solving practical problems; but it is not necessarily concerned with the advancement of knowledge for its own sake. This is certainly true in the area of military workforce planning, and it raises the question of whether it should truly be considered as "research." Although an academic may focus their research on a military workforce planning problem, most work done in the field is in direct response to military clients' questions; and as Manson (2006) comments more generally about operational researchers outside of academia, practitioners generally have little interest in whether their work is considered "research" or not.

Even so, a strong argument can be made to suggest that the field is indeed research - more specifically, an implementation of design science research (also referred to as design research or constructive research; Vaishnavi and Kuechler 2004). Although it is a multidisciplinary field with broad applications, design science research is frequently applied to the development of information systems, including analytics-related products such as business intelligence tools (Mwilu et al. 2016). Manson (2006) proposes that field of operational research fits in well with the design science research paradigm, and we suggest that this is true more generally for MWFA.

Design science research involves creating an "artifact" and analyzing the use of that artifact to make further improvements. Through the process of analyzing how well the artifact meets its intended purpose, new knowledge is gained, and this knowledge is used to further develop the artifact and to inform solutions to problems. When applied to the MWFA domain, the artifact might be a method of integrating data from various sources, an algorithm for forecasting attrition, a model that simulates the flow of personnel through a training system, etc.

Vaishnavi and Kuechler (2004) compare the design science research perspectives with positivist and interpretive research perspectives and demonstrate that the design science philosophical assumptions are unlike the others (and in fact change throughout the execution of the research process). They describe the epistemology as "knowing through making." Axiologically, design science researchers value progress (e.g., improvements to a method or model) and utility over absolute truths. In the field of MWFA, of paramount importance is providing value to military planners in the form of information or recommendations, delivered in a timely manner to enable improved decision-making.

\section{MWFA Research Process}

Numerous frameworks have been used to describe the process of conducting research in analytics-related fields, and most of them have several key elements in common: They begin with developing an understanding of the problem and the data; they involve the creation of an artifact (e.g., a model) and the evaluation of that artifact; and they end with the implementation of a solution. 
MWFA practitioners rely heavily on military personnel data that are collected in corporate human resource information systems and other data repositories. Due to this data-driven nature, the Cross Industry Standard Process for Data Mining (CRISP-DM) process (IBM n.d.) appears largely suitable. It consists of six phases constructed as a cycle: business understanding, data understanding, data preparation, modeling, evaluation, and deployment. Not all MWFA activities will be related to the data science field that the CRISP-DM was intended for, but the general principles remain useful.

Drawing from some phases of the CRISP-DM process (IBM n.d.) in combination with some phases from the Peffers et al. (2007) framework for describing design science research, the following framework provides a useful illustration of the main phases of research in MWFA:

- Business understanding: This phase involves defining the question being asked (or alternatively, the problem to be solved), setting objectives, and making a preliminary plan to achieve them. Relevant information is gathered, which may come from clients, subject matter experts, policy documents, or previous studies (both from MWFA and from related fields such as organizational psychology and the social sciences). Practitioners should aim to understand the perspective of the end user, often a military workforce planner, and how the solution will be used, in order to be able to provide the most appropriate answer.

- Data understanding: The objective of this phase is to gather the data needed to solve the problem and to assess their completeness, quality, and limitations. By the end of this phase, practitioners should have a sense of how well the data will help to solve the problem, and may already have an idea for how limitations can be overcome.

- Data preparation: This phase involves preparing the data to the point where it can be used in a model or other artifact. Data preparation may involve merging data sets (and dealing with any technical issues that arise), selecting a subset of data (e.g., a specific segment of the military population to be studied further), dealing with missing values (e.g., by ignoring the data point, or by estimating its value based on other information), etc. In the CRISP-DM process for data mining, data preparation is estimated to take $50 \%-70 \%$ of a project's time and effort (IBM n.d.). This is often true for MWFA projects as well.

- Design, development, and demonstration: In the business understanding phase, the practitioner will have come up with a preliminary plan; and after having prepared the data, it will be possible to determine whether the plan is still appropriate. The plan may need to be amended if, for example, there is insufficient data to implement the desired solution. Further, given that the MWFA is often done to support military users' operational needs, it is necessary to ensure that it will be feasible to deliver a solution to them in a timely manner. At this point, an artifact is created and an initial solution (e.g., set of modeling or analysis results) is produced.

- Evaluation: In this phase, practitioners verify that the solution meets the objectives and is correct. Experienced practitioners will have a sense of what "looks 
right," and tests can be done to ensure the behavior of the artifact is as expected. When unexpected behavior is found, the cause should be identified. It could be that an error was made or that a data limitation was overlooked. During this stage, errors and areas for potential refinement may be identified, and the practitioner would then go back to the previous phase to implement improvements. The required level of accuracy should be considered - there will be situations where the value added by increased accuracy will not justify the amount of time and effort needed to achieve it. After the solution has been found to be satisfactory, practitioners should identify the main findings; not only those to be passed on to the military user, but also those of interest to other MWFA practitioners or others involved in military workforce management.

- Deployment: The final phase involves communicating the findings (as well as recommendations where applicable) to the military client, often in the format of a report, presentation, or even an informal email. Technical details of the method are usually not included in reports for clients; however, they may be included in a separate scientific report intended for other MWFA practitioners (including in the academic literature in some cases). This way, the knowledge gained through the process, whether it be an element of data understanding, a process, or a methodological development, can be applied for other studies. In some cases, future outcomes will be monitored; for example, if an attrition forecast was made, the actual attrition will be measured so that the accuracy of the forecast can be evaluated, which could then inform the approach taken for subsequent forecasts.

Notably, several of the above phases can be interrelated and may be done in parallel (or iteratively). For example, discoveries may be made during the data preparation phase that increase data understanding. In cases where particularly complicated data sets are manipulated, the process of preparing the data may itself be a major component of the design, development, and demonstration phase, or new data requirements may be identified during this phase, requiring additional data preparation. And of course, findings from the evaluation phase may lead to increased data understanding, a need for additional data preparation, and further design, development, and demonstration.

\section{Data Considerations in Military Workforce Analytics}

Most military organizations collect a wealth of data about their members. Corporate human resource information systems typically hold data on military members' demographic details (e.g., age, sex, marital status) and career histories (e.g., hire date, release date, occupation, rank, unit, position). Other systems may also contain useful data. For example, electronic health records for military members may be housed separately from the human resource information system for privacy or other reasons. Other information systems may contain data for operational purposes, such as performing recruiting functions, managing military taskings, or tracking readiness for deployment. Data on financial transactions may be housed in yet another 
information system. Valuable sources of data may also be collected in spreadsheets managed by an individual for a specific purpose (e.g., schedules for a training institution), and subject matter experts can help MWFA practitioners interpret data and understand processes and procedures pertaining to the topic being studied.

Merging these rich data sources for MWFA is not without challenges. Data systems are frequently disconnected from each other, presenting difficulties with integration. A study by the RAND Corporation (Lim et al. 2019) noted that the military services of the USA identified the disconnected nature of their various datasets as potentially preventing valuable information from being used for analytical purposes. In some cases, it may be challenging, or impossible, for practitioners to gain authorization to access data, particularly when there are concerns about security or privacy (e.g., medical records).

Even when data can be accessed, practitioners are likely to encounter limitations. Given the focus on military personnel, it would be ideal to have high-quality data on the entire career of each current and recently serving member. Given that a military career may last 35 years or even longer in a few cases, this is impossible today since human resource information systems have not been in place for that long, or at least not in their current forms. In addition, data loss may occur any time a system is replaced, although this can be minimized if efforts are made to ensure good data management. As in other domains, data quality and latency can also present problems.

MWFA practitioners should be aware of the organizational context - for example, policy changes affecting the workforce and changes in administrative practices during the timeframe for which the data were collected. This can be important for a range of analytics activities, including interpreting descriptive statistics and selecting historical data for use in a model. In 2010, for example, the New Zealand Defence Force implemented a civilianization program that resulted in a larger than expected increase in attrition, which was attributed to the program's negative impact on morale; in 2012, attrition then decreased after organizational changes were implemented to improve retention (Defence Communications Group 2013). Such policy changes must be taken into account when developing a graph of historical attrition rates for senior leaders or choosing attrition rates for a model used to determine the force's future intake needs. Similarly, a peculiarity in the data may be the result of administrative changes, such as a modification to the training system or a change in the meaning or usage of an administrative code, or a process-related reason for missing values in a dataset.

Naturally, it takes time for practitioners to learn the organizational context and administrative changes that can bear on a particular study, which presents challenges for onboarding new practitioners. Policy documents can be useful (although it can be difficult for practitioners to know exactly what to search for, and obsolete policy documents are not always maintained on corporate websites). Subject matter experts can be valuable sources of advice, and corporate knowledge will be gained over the course of one's career. As Hill (2020, p. 16) remarks, "algorithms will never replace human knowledge and experience." 


\section{Military Workforce Analytics Researchers}

MWFA researchers may be civilian or military. They come from a range of academic backgrounds, including mathematics, physics, engineering, computer science, and data science, as well as operational research and management science. On top of having knowledge of analytical techniques, practitioners must have strong problem solving skills and an ability to think critically. Strong interpersonal skills are a necessity, since work is often done in interdisciplinary teams and in close collaboration with military clients and subject matter experts. Similarly, strong communication skills are needed to explain research and analysis findings to military practitioners who may not have strong research backgrounds. Creativity, agility, and perseverance are useful traits; data sets can be challenging to access, integrate, and generally make sense of, so a willingness to "dig deeper" to truly understand the data, and an ability to find workarounds to data limitations, is helpful.

\section{Applications of MWFA}

This section discusses several common areas where MWFA approaches are used. The intent is to provide a sense of the scope of the domain and an understanding of the ways in which analytics products are important to military leaders' decisionmaking.

\section{Population and Attrition Monitoring}

Although normally considered the most basic form of analytics, descriptive statistics remain relevant to many organizations (Pluralsight n.d.), and military organizations are no exception. Armed forces typically monitor general statistics pertaining to their personnel. In some cases, reports are published online and made accessible to the public (Defense Manpower Data Center n.d.; Department of Defence 2020; Ministry of Defence 2020). These types of reports are useful for monitoring general trends in the workforce; for example, they can highlight changes in attrition, illustrate changes in the population over time, and show how the actual population compares to the desired population on key aspects. Statistics on specific occupations - for example, the UK's identification of "pinch point" trades (National Audit Office 2018), Canada's Establishment and Strength Report (unpublished), and Australia's Employment Category Status Report (Australian National Audit Office 2017) - can be used to monitor which occupations are chronically understaffed, which helps military workforce planners to identify occupations that may need additional attention. Even though these standardized reports may appear straightforward, it is typical for MWFA practitioners to be involved in their development since they have the expertise to correctly extract data from the human resource information system and to note any necessary definitions or caveats. 
Military leaders are often interested in seeing how their organizations compare with those of other nations, so online resources available to the public are valuable for MWFA practitioners seeking answers to such queries. One topic of particular interest for drawing comparisons is the participation of women. This is an area with many opportunities for MWFA practitioners to collaborate with colleagues in other fields, such as the social sciences. A report from the North Atlantic Treaty Organization (NATO) Committee on Gender Perspectives includes various descriptive statistics on this topic from many nations, as well as information from other fields for example, comparing nations' polices of gender integration, work-life balance initiatives, and the prevention of sexual harassment and sexual abuse (NATO 2020). Some nations have published comprehensive multi-disciplinary reports on the gender-related issues in the military (Ministry of Defence 2014; Australian Human Rights Commission 2012), and countless other studies on the topic are available (Fasting and Sand 2010). These information sources can be useful for adding context to help explain underlying reasons for numbers that vary across nations.

Another topic that warrants comparison across nations is attrition. When searching for attrition rates of other nations' militaries, MWFA practitioners will likely find them in online statistical reports or from other sources, such as unpublished materials from conferences or meetings, personal communications with counterparts in other nations, or even media articles. Practitioners should interpret these statistics with caution, however. Although several research projects have proposed ways to measure attrition (Okazawa 2007; Vincent et al. 2018), there is no standardized method used across armed forces internationally, making it difficult to make direct comparisons.

Ideally, practitioners would compute the attrition rates of other militaries with the method used in their own, using data from other nations (e.g., raw population and release statistics as applicable); however, these data are not usually readily available.

\section{Attrition Analysis}

In addition to the high-level attrition monitoring and international benchmarking discussed above, MWFA practitioners may become involved in more in-depth attrition studies, which can answer questions like:

- How do attrition behaviors vary between men and women?

- How many members remain in the military after 20 years of service?

- Do members who enrolled through subsidized education programs remain in the military longer than those who enrolled through other entry plans?

- Which members are most or least likely to remain until the end of their first term?

There are several methods that can be used to approach questions in this area. For example, a simple depiction of attrition rates by years of service can effectively illustrate the career points at which members have a higher propensity to leave. Serré and Straver (2018) used this approach to demonstrate that women are more likely to 
leave the Canadian Armed Forces beyond the 20 years of service point. A survival analysis involves tracking attrition of a group over time. Schofield et al. (2018) used this approach for the US Air Force to examine attrition over a 20-year time frame to provide insights into occupations requiring special attention; Steder (2014) used it to show the difference in "dropout" rates between men and women from the point of showing interest in the Norwegian Armed Forces to the point of completing one year of military service; and Straver and Pilat (2018) used it to explore differences in the lengths of service of officers who joined the military through different entry plans. Logistic regression can be used to identify the predictors of attrition. Hoglin and Barton (2013) used this technique to determine that members with a low level of education, low aptitude score, and low psychologist interview rating on enlistment are more likely to leave the Australian Defence Force in their first term.

Here again, attrition studies have a high potential for collaboration between MWFA practitioners and researchers in other domains. While MWFA focuses on numbers of releases and attrition rates, research from other disciplines helps to explain the reasons why members leave the military.

\section{Estimating Future Attrition}

Several aspects of the personnel management system, including recruitment, training, and promotion, are driven at least in part by attrition; thus, it is important to be able to anticipate attrition in order to plan these functions. In some cases, military planners may wish to know how many members will leave the organization within the next two years, or they may be interested in how attrition will change in the long term. In other cases, they will be interested in only one subset of the population, such as a specific occupation. MWFA analysts themselves may also need to know about future attrition, since this information is often a required input for a model intended for a different purpose such as for recruitment recommendations.

Several analytics-based methods are suitable for estimating future attrition. Okazawa (2007) and Fang and Okazawa (2009) proposed a method for estimating the number of future releases by using each member's years of service as a predictor, the rationale being that members are most likely to be released at the end of a term of service, which typically coincides with a specific number of years of service. Some practitioners have used advanced statistical methods or machine learning techniques - Diener and Calitoiu (2017) used logistic regression to predict attrition up to two years into the future; Pechacek et al. (2019) used a neural network model to calculate the probability that a member would remain in the military after a specified period of time, based on some administrative data on that member's career; and Smith et al. (2018) used a binary logistic regression model, classification tree, and a random forest classification model to predict the probability that a member would be released prior to the completion of their first term.

It is the responsibility of the MWFA researcher to determine which method is most appropriate to answer the client's question. Factors to be considered include the required length of the forecast (since some methods are more suitable for short-term 
forecasts, while others are more suitable for long-term forecasts), the amount of historical data available for the population of interest (since simpler models are more appropriate in cases where the volume of data is limited), and the way that the information will be used (since it may not always be an efficient use of resources to devote large amounts of time to developing a forecast with a very high level of accuracy).

\section{Intake Planning}

Intake planning, that is, the process of determining how many members need to be recruited to achieve the required number of personnel in the organization, is a crucial part of the military workforce planning cycle. The process can be very complex with many factors to be taken into account. Firstly, military organizations are faced with overall constraints. For example, in the Estonian Defence Forces, the personnel costs should not exceed one third of the defense budget (Viljar 2017). The United Kingdom Armed Forces have a target of 144,200 full-time trained personnel (Dempsey 2020), while the Regular Force of the Canadian Armed Forces is constrained to 71,500 trained and untrained personnel (Department of National Defence 2017). Secondly, within a military organization, each occupation requires a specific number of trained members, and this number can change over time. Further, there are numerous streams through which a person can join an occupation in the armed forces (e.g., subsidized education programs, direct entry, transfer from another occupation); these too are subject to change. Each stream has its own training path, with its own expected training success rate, length of training, and training capacity. At the same time, many military organizations have additional goals (e.g., for the representation rate of women) to be considered in intake planning.

MWFA practitioners have a role to play by providing direct support to military planners in quantifying the intake needs. Because of its complexity, it is not practical to model the details of the entire personnel production system; rather, simple interactive tools that allow military planners to conduct "what-if" analysis with instantly updated results are useful for this purpose.

Depending on the organization's way of operating, such tools are useful for intake planning at different levels. At the total-force level, Straver and Pilat (2017) developed a model to determine the future intake of men and women needed to achieve the Canadian Armed Forces' representation goal of $25.1 \%$ women, accounting for expected attrition and planned growth to the forces overall. To support planning at the occupation level, Okazawa et al. (2018) developed a model to enable military planners to determine the intake needs for occupation through various entry plans, accounting for attrition from the trained population, attrition during training, length of training, and training capacity.

Aside from a brief mention in a report from the NATO Research and Technology Organization (NATO 2012), there is scant literature on these tools. This is likely because this type of model development is less academic in nature than some other 
analytics-based methods used to support military workforce planning, which will be discussed later in this chapter.

\section{Support to Recruiting}

While the previous section focused on estimating intake requirements, this section focuses on how analytics can inform recruitment strategies to meet those needs. Different nations recruit in very different ways, so there is no one-size-fits-all approach. For example, nations with all-volunteer forces will face different problems than those that use conscription. In Estonia, conscripts gain skills (e.g., communication and information technology) that they will use in civilian life (GlobalSecurity. org 2014), while all-volunteer forces struggle to recruit people with these skillsets (Straver and Arseneau 2019). Further, different nations are interested in recruiting from different segments of the population, having varying requirements for age, education, physical fitness, etc. Some nations accept women into all positions, while others have restrictions on roles for women. Factors such as unemployment rates among young people and the public's perception of the military (e.g., extent to which military service is considered a desirable occupation; perceptions regarding the role of women in the military) have an impact on the challenges that armed forces face in their recruitment efforts (Smith and Heinecken 2014). Finally, the COVID-19 pandemic has had an impact on military organizations around the world to varying extents due to the need to cease or reduce normal recruitment and/or training activities.

For all-volunteer forces in particular, artificial intelligence (e.g., machine learning) is increasingly being used to support recruiting functions, but there is potential for more to be done in this area. A comprehensive study by the RAND Corporation highlights how technological advancements in this field can be leveraged to transform outreach and prospective recruit management strategies (Lim et al. 2019). Already, studies have been conducted to identify geographic areas with high potential for quality recruits (Fulton 2016; Monaghan 2016; McDonald et al. 2017; Ueno et al. 2021) and to identify potential channels for reaching women through analysis of social media behaviors (Ueno et al. 2021).

\section{Modeling Force Structures and Training Systems}

This section focuses on problems in the areas of force structures and training systems, which can be solved by modeling and simulation. Force structure models represent the flow of personnel through a military hierarchy, and training models represent the flow of personnel through a training system. These areas are interrelated to an extent - a military organization's ability to sustain its force structure (i.e., to fill the positions within its ranks by qualified personnel) is dependent in part on the capacity of the training system to prepare members for those ranks. For this reason, force structure models often, but not always, include a representation of the training 
system. Some force structure models also include elements of force employment, for example, to determine whether sufficient personnel resources will be available for deployment on operations. (As examples, see Scales et al. (2011) and Filinkov et al. (2011).) The level of detail included in different components of the model will vary depending on the problem to be solved.

Force structure models account for the attrition, promotion, and intake of personnel and, in some cases, training or force employment, as noted above. They can answer question such as:

- How many promotions will be needed to fill the ranks?

- How many new members are needed each year to sustain the force structure?

- How many years do members typically spend in each rank? How will this change if attrition rates change?

- How long will it take to transition to a new force structure?

When the focus is on training systems, typical questions include:

- What are the main bottlenecks in the training system?

- How many courses need to be run to generate the required number of trained personnel, and how might this change over time?

- How can resources (e.g., instructors, equipment) be allocated to optimize the throughput of the training system?

- If a course needs to be cancelled or delayed, what downstream effects can be anticipated?

It may be necessary to spend a considerable amount of time gathering, cleaning, and formatting the input data to be used in the model (Lesinski et al. 2011), and this is particularly true for modeling training systems. MWFA practitioners will likely need to invest a considerable amount of time in studying the existing training system and in understanding the constraints and limitations of changes that are to be considered. Okazawa (2013a) notes that typical simulation models of training systems require data on the current population undergoing training, details about courses (e.g., capacity and other resource limitations, schedule, duration, failure/ withdrawal rate), and details on the ways in which trainees advance from one course to the next. Some of the necessary information is not likely to be available in a corporate database, so it is often necessary to consult subject matter experts (Okazawa 2013b). Conversely, much of the information required for force structure models (e.g., historical attrition rates, promotion criteria) will be available from corporate human resource information systems, policy documents, or other readily available sources. Of course, models that incorporate aspects of both training systems and force structures will be more complex, increasing the time and effort required in developing the model.

MWFA practitioners will need to determine the level of detail that is needed to address the research questions. When the focus is on force structures, it is usually appropriate to model training in a relatively simple way, if at all, and vice versa. 
Regardless of the area of focus, a high level of detail may not always be necessary and may be counterproductive. As noted in Lesinski et al. (2011), additional detail does not necessarily contribute meaningfully to the research questions; further, valid, authoritative data may not exist, and too much detail may be computationally prohibitive for larger models.

The most common modeling approaches used for these types of problems are system dynamics, discrete event simulation, and Markov chain modeling. All methods aim to represent the dynamics of the system. For example, the attrition of a member creates a vacancy; that vacancy is filled through the promotion of a qualified member from the rank below, which creates a vacancy to be filled through the promotion of a qualified member from the next rank below, and so on, until positions at the lowest rank are filled by new members (often after a period of training).

In system dynamics, a system is represented by a set of stocks (e.g., the number of members of a particular rank, or the number of members taking a specific course) and flows (e.g., the number of members advancing from one rank to the next, or the number of members moving from one course to another). Armenia et al. (2012) used this approach to inform policy decisions pertaining to the downsizing of the Italian Air Force, and Séguin (2015) used it to model the pilot occupation of the Canadian Armed Forces, assessing the impact of reduced budgets in combination with high numbers of pilots completing the initial phases of their training.

Discrete event simulation models treat each member as an individual entity as they move through the system. Each individual can be assigned numerous attributes that can change over the course of (simulated) time. For example, Serré and Gauthier (2016) used discrete event simulation to determine how long it would take for the Musician occupation in the Canadian Armed Forces to transition to a new rank structure that had undergone major changes. Lesinski et al. (2011) used it to model the flow of US Army officers from their commissioning source to their first unit of assignment. For the Royal Australian Navy, Lalbakhsh et al. (2018) used it to determine the number of members who could complete conversion training to become qualified to fly a new type of aircraft.

In Markov chain models, personnel flows are based on probabilities; for example, members of a particular rank will have a specified probability of attrition, or probability of advancement to the next rank. Zais and Zhang (2016) used a Markov chain model to study monetary incentives of stay-or-leave decisions, estimating the financial impact of staying or leaving for each stage of a member's career, taking into account the future career progression and retirement benefits versus expected pay in the civilian sector. The Canadian Armed Forces use a Markovian planning tool to enable occupation planners to determine whether long-term sustainability problems can be expected in a proposed force structure based on the occupation's attrition rates and promotion criteria (Boileau and Isbrandt 2020). Škulj et al. (2008) found that it was not possible to fully sustain the desired force structure of some segments of the Slovenian Armed Forces, which provided evidence for what experts and decisionmakers were already somewhat aware of anecdotally or based on operational knowhow. 
While all of these approaches have been used successfully to solve workforce planning problems, they have different strengths and weaknesses, and different practitioners have different preferences. Markov chain models seem to be the least popular of the three methods discussed in this section. Although Guerry and De Feyter (2009) suggest that a Markovian force structure model is an interesting tool for gaining insights (e.g., through what-if analysis), they acknowledge that it has some critical limitations. Wang (2005) argues that system dynamics is most suitable in cases where the effects of feedback are important to consider; while Jnitova et al. (2017) prefer the flexibility of discrete event simulation, Jajo (2015) prefers discrete event simulation for its ability to track and monitor individuals' attributes and for its suitability for modeling small populations.

Some practitioners have discussed the suitability of system dynamics versus DES approaches, both for military workforce planning problems (Jajo 2015; Jnitova et al. 2017) and in the broader field of modeling and simulation (Chahal and Eldabi 2008; Tako and Robinson 2009; Greasley 2009). It is generally accepted that system dynamics is a suitable approach for strategic-level problems where the goal is to understand the overall functioning of the system and the interactions within it, whereas discrete event simulation offers a higher level of granularity for problems at the operational level (Helal and Rabelo 2017). Hybrid models that include elements of both approaches have also been used to solve problems in this domain (Škraba et al. 2007).

\section{Additional Applications}

The previous sections presented examples of how analytics support ongoing functions in military workforce planning. MWFA practitioners also conduct studies to answer specific questions or to support specific decisions. Some studies are descriptive in nature, while others require a bespoke model (or a variation of one of the approaches discussed above). They may be designed to help evaluate the effectiveness of a program, determine the effects of a past change to a policy or process, estimate the impact of a policy change being considered, or serve some other purpose. Some analyses may take a matter of hours for a practitioner to complete, whereas others may take a year or more. Following are a few examples of such studies:

- Diener (2017) constructed a mathematical model to determine how many bilingual members would be needed to fill the number of bilingual positions in a specified rank and occupation of the Canadian Armed Forces, taking into account the practice of rotating personnel out of positions every few years.

- Bender and Kerzner (2002) studied the long-term impact of increasing the compulsory retirement age and found that the effect on promotion rates would be minimal. 
- To assist in the planning of a benefit being considered for members who suffered a career-ending injury, Okazawa et al. (2018) developed a Markov chain model to estimate the total years of service and rank that a member would likely have attained had the injury not occurred, accounting for the member's history of advancing quickly (or slowly) through the ranks.

\section{Summary}

This chapter presented an overview of the role that analytics plays in military workforce planning. As an applied research field, the objective is to support military leaders by giving them insights about their personnel and to support their decisionmaking in areas from intake planning and recruitment to the design of force structures and training systems. For this reason, with the exception of cases where relatively advanced techniques are used, it is difficult to find examples of MWFA applications in the scientific literature. In many cases, solutions in the form of graphical representations of complicated data or bespoke spreadsheet models are appropriate for answering the question at hand. While these are generally of interest to the users and practitioners within a local MWFA community, they are not generally of interest in the academic domain.

Underlying all analytics in this domain is data. Although military organizations around the world collect data about their personnel, MWFA practitioners face challenges with accessing, integrating, cleaning, and generally making sense of the data. It is hoped that some of these issues will diminish over time, with more resources being dedicated to data management and governance given military organizations' increasing interest in data-enabled decision-making. However, even if improvements can be made to data access and quality, practitioners will still need to develop a deep understanding of the data, and the organizational and policy context surrounding its collection, which can be difficult for those new to the field.

This chapter discussed a few methods commonly used in the field, ranging from descriptive statistics to machine learning to modeling and simulation. Advancements in the field of data science will provide MWFA practitioners with new ways of exploiting data on military personnel, but they should bear in mind that simple solutions and traditional approaches still provide great value. Novel tools are not "magic bullets" that obviate the need for collaborative approaches to problemsolving that include decision-makers, military planners, and subject matter experts. Making the most of the data available, the human knowledge of the problem to be solved, and an understanding of the military workforce management system is the best way to ensure that military clients receive sound advice. 


\section{Cross-References}

Challenges in HRM in Military Organizations

Economics, Logistics, and (Human Resources) Management in Military Sciences

Military Personnel

What is Military Behavioural Sciences?

\section{References}

Armenia, S., Centra, A., Cesarotti, V., De Angelis, A., \& Retrosi, C. (2012). Military workforce dynamics and planning in the Italian air force. In Proceedings of the 30th international conference of the system dynamics society (pp. 22-26). St. Gallen: System Dynamics Society.

Australian Human Rights Commission. (2012, August 8). Review into the treatment of women in the Australian Defence Force: Phase 2 report. Retrieved February 11, 2020, from https:// defence.humanrights.gov.au/sites/default/files/adf-complete.pdf

Australian National Audit Office. (2017, March 27). Army's workforce management (ANAO Report No. 44 2016-17). Retrieved February 10, 2020, from https://www.anao.gov.au/sites/default/ files/ANAO_Report_2016-2017_44_0.pdf

Bender, P. R. S., \& Kerzner, L. F. (2002). Career flow implications of terms of service proposals for non-commissioned members (operational research division project report 2002/08). Ottawa: Operational research division, Directorate of Operational Research (Corporate).

Boileau, M., \& Isbrandt, S. (2020). Verification and validation of the occupation structure sustainability model (director general military personnel research and analysis scientific report DRDCRDDC-2020-R017). Ottawa: Defence Research and Development Canada.

Chahal, K., \& Eldabi, T. (2008). Which is more appropriate: A multi-perspective comparision between system dynamics and discrete event simulation. In Z. Irani, S. Sahraoui, A. Ghoneim, J. Sharp, S. Ozkan, M. Alie, \& S. Alshawi (Eds.), Proceedings of the European and Mediterranean conference on information systems 2008. Uxbridge: Brunel University.

Defence Communications Group. (2013, January 30). Audit report reinforces what defence personnel have told their leaders. Retrieved February 6, 2020, from http://www.nzdf.mil.nz/mediacentre/news/2013/20130131-arrwdphtk.htm

Defense Manpower Data Center. (n.d.). DoD personnel, workforce reports \& publications. Retrieved February 11, 2020, from https://www.dmdc.osd.mil/appj/dwp/dwp_reports.jsp

Dempsey, N. (2020). UK defence personnel statistics. Retrieved 18 February, 2021, from https:// commonslibrary.parliament.uk/research-briefings/cbp-7930/.

Department of Defence. (2020, September 21). Annual report 19-20: Chapter 7 - Strategic workforce management. Retrieved February 18, 2021, from https://www.defence.gov.au/ annualreports/19-20/DAR_2019-20_Complete.pdf

Department of National Defence. (2017). Strong, secure, engaged: Canada's defence policy. Retrieved February 18, 2020, from http://dgpaapp.forces.gc.ca/en/canada-defence-policy/docs/ canada-defence-policy-report.pdf

Diener, R. (2017). Bilingual staffing within the Canadian Armed Forces. Journal of Applied Operational Research, 9(1), 2-10.

Diener, R., \& Calitoiu, D. (2017). Accurate predictions of naval reserve attrition (director general military personnel research and analysis scientific letter DRDC-RDDC-2017-L287). Ottawa: Defence Research and Development Canada.

Fang, M., \& Okazawa, S. (2009). Forecasting attrition volume: A methodological development (director general military personnel research and analysis technical memorandum DGMPRA TM 2009-025). Ottawa: Defence Research and Development Canada. 
Fasting, K., \& Sand, T. S. (2010). Gender and military issues - A categorized research bibliography. Oslo: The Norwegian Defence University College Norwegian School of Sport Sciences Defence Institute.

Filinkov, A., Richmond, M., Nicholson, R., Alshansky, M., \& Stewien, J. (2011). Modelling personnel sustainability: A tool for military force structure analysis. Journal of the Operational Research Society, 62(8), 1485-1497. https://doi.org/10.1057/jors.2010.85.

Fulton, B. M. (2016, June). Determining market categorization of United States ZIP codes for purposes of army recruiting. Retrieved February 17, 2020, from https://apps.dtic.mil/dtic/tr/ fulltext/u2/1026576.pdf.

GlobalSecurity.org. (2014). Estonia - Military personnel. Retrieved 15 February, 2021, from https://www.globalsecurity.org/military/world/europe/et-personnel.htm.

Greasley, A. (2009, July). A comparison of system dynamics and discrete event simulation. In O. Balci, M. Sierhuis, X. Hu, \& L. Yilmaz (Eds.), Proceedings of the 2009 Summer Computer simulation conference (pp. 83-87). Istanbul: Society for Modeling \& Simulation International.

Guerry, M. A., \& De Feyter, T. (2009). Markovian approaches in modeling workforce systems. Journal of Current Issues in Finance, Business and Economics, 2(4), 351-370.

Helal, M., \& Rabelo, L. (2017). Synchronizing discrete event simulation models and system dynamics models. In Proceedings of the 2017 international conference on industrial engineering and operations management (IEOM) (pp. 602-613).

Hill, R. R. (2020). Modern data analytics for the military operational researcher. In N. M. Scala \& J. P. Howard (Eds.), Handbook of military and defense operations research (pp. 3-18). Boca Raton: Taylor \& Francis Group.

Hoglin, P. J., \& Barton, N. (2013). First-term attrition of military personnel in the Australian Defence force. Armed Forces and Society, 41(1), 43-68. https://doi.org/10.1177/ $0095327 X 13494743$.

IBM. (n.d.). IBM SPSS modeler CRISP-DM guide. Retrieved February 11, 2021, from https://www.

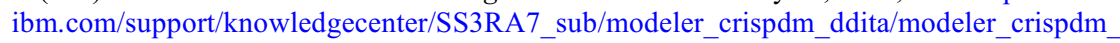
ddita-gentopic1.html

Jajo, N. (2015). The trade-off between DES and SD in modelling military manpower. Management Science Letters, 5. https://doi.org/10.5267/j.msl.2015.

Jnitova, V., Elsawah, S., \& Ryan, M. (2017). Review of simulation models in military workforce planning and management context. Journal of Defense Modeling and Simulation, 14(4), 447-463. https://doi.org/10.1177/1548512917704525.

Lalbakhsh, P., Mak-Hau, V., Séguin, R., Nguyen, V., \& Novak, A. (2018). Capacity analysis for aircrew training schools-estimating optimal manpower flows under time varying policy and resource constraints. 2018 Winter Simulation Conference (WSC), 2285-2296. https://doi.org/10. 1109/WSC.2018.8632235.

Lesinski, G., Pinter, J., Kucik, P., \& Lamm, G. (2011, July). Officer accessions flow model (Operations Research Center of Excellence Technical Report DSE-TR-1103). Retrieved February 17, 2020, from https://apps.dtic.mil/sti/pdfs/ADA546536.pdf

Lim, N., Orvis, B., \& Curry Hall, K. (2019). Leveraging big data analytics to improve military recruiting (RR-2621-OSD). Retrieved February 17, 2020, from https://www.rand.org/pubs/ research_reports/RR2621.html

Manson, N. J. (2006). Is operations research really research? Orion, 22(2), 155-180. https://doi.org/ $10.5784 / 22-2-40$.

McDonald, J. L., White, E. D., Hill, R. R., \& Pardo, C. (2017). Forecasting US Army enlistment contract production in complex geographical marketing areas. Journal of Defense Analytics and Logistics, 1(1), 69-87. https://doi.org/10.1108/JDAL-03-2017-0001.

Ministry of Defence. (2014, February). Maximising opportunities for military women in the New Zealand Defence force. Retrieved February 11, 2020, from http://www.nzdf.mil.nz/ downloads/pdf/public-docs/2014/maximising-opportunities-military-women-nzdf.pdf 
Ministry of Defence. (2020, December 17). Quarterly service personnel statistics: 2019. Retrieved February 18, 2021, from https://www.gov.uk/government/statistics/quarterly-service-personnelstatistics-2020

Monaghan, E. M. (2016, September). Estimating the depth of the navy recruiting market. Retrieved 17 February 2020, from https://apps.dtic.mil/dtic/tr/fulltext/u2/1029859.pdf

Mwilu, O. S., Comyn-Wattiau, I., \& Prat, N. (2016). Design science research contribution to business intelligence in the cloud-A systematic literature review. Future Generation Computer Systems, 63, 108-122. https://doi.org/10.1016/j.future.2015.11.014.

National Audit Office. (2018, April 18). Ensuring sufficient skilled military personnel (HC 947 Session 2017-2019). Retrieved February 17, 2020, from https://www.nao.org.uk/wp-content/ uploads/2018/04/Ensuring-sufficient-skilled-military-personnel.pdf

North Atlantic Treaty Organization. (2012). NATO human resources (manpower) management (RTO-TR-SAS-059). Retrieved February 18, 2021, from https://www.sto.nato.int/publica tions/STO\%20Technical\%20Reports/RTO-TR-SAS-059/\$TR-SAS-059-ALL.pdf

North Atlantic Treaty Organization. (2020). Summary of the national reports of NATO member and partner nations to the NATO committee on gender perspectives 2018. Retrieved February 16, 2021, from https://www.nato.int/nato_static_fl2014/assets/pdf/2020/7/pdf/200713-2018Summary-NR-to-NCGP.pdf

Okazawa, S. (2007). Measuring attrition rates and forecasting attrition volume (Centre for Operational Research and Analysis Technical Memorandum DRDC CORA TM 2007-02). Ottawa: Defence Research and Development Canada.

Okazawa, S. (2013a). Modelling and simulation for military human resource planning. In J. P. Johnston \& K. Farley (Eds.), Military human resource issues: A multinational view (pp. 19-37). Kingston: Canadian Defence Academy Press.

Okazawa, S. (2013b, December). A discrete event simulation environment tailored to the needs of military human resources management. 2013 Winter Simulations Conference (WSC), 2784-2795. https://doi.org/10.1109/WSC.2013.6721649.

Okazawa, S., Straver, M., \& Arseneau, L. (2018). Occupation promotion recruitment and attrition model (OPRAM): A replacement for the Royal Canadian Navy long-range planning model (director general military personnel research and analysis scientific report DRDC-RDDC-2018R273). Ottawa: Defence Research and Development Canada.

Pechacek, J., Gelder, A., Roberts, C., King, J., Bishop, J., Guggisberg, M., \& Kirpichevsky, Y. (2019, June). A new military retention prediction model: Machine learning for high-fidelity forecasting (Institute for Defence Analyses IDA Document NS D-10712). Retrieved February 17, 2020, from https://www.ida.org/-/media/feature/publications/a/an/a-new-military-retentionprediction-model_machine-learning-for-high-fidelity-forecasting/d-10712.ashx

Peffers, K., Tuunanen, T., Rothenberger, M., \& Chatterjee, S. (2007). A design science research methodology for information systems research. Journal of Management Information Systems, 24, 45-77.

Pluralsight. (n.d.) 4 levels of analytics you need for better decision making. Retrieved 11 February, 2020, from https://www.pluralsight.com/blog/data-professional/data-informed-decisions

Scales, C., Okazawa, S., \& Ormrod, M. (2011). The managed readiness simulator: A force readiness model. In Proceedings of the 2011 winter simulation conference (pp. 2514-2524). https://doi. org/10.1109/WSC.2011.6147960.

Schofield, J. A., Zens, C. L., Hill, R. R., \& Robbins, M. J. (2018). Utilizing reliability modeling to analyze United States air Force officer retention. Computers \& Industrial Engineering, 117, 171-180. https://doi.org/10.1016/j.cie.2018.01.013.

Séguin, R. (2015). PARSim, a simulation model of the Royal Canadian Air Force (RCAF) pilot occupation: An assessment of the pilot occupation sustainability under high student production and reduced flying rates. In Proceedings of the 5th international conference on operations research and Enterprise systems (pp. 51-62). https://doi.org/10.5220/0005234700510062. 
Serré, L., \& Gauthier, M. (2016). Transition time for the musician occupation's new rank structure under two intake scenarios (director general military personnel research and analysis scientific letter DRDC-RDDC-2016-L227). Ottawa, ON: Defence Research and Development Canada.

Serré, L., \& Straver, M. (2018). Attrition patterns of women in the Canadian Armed Forces. Res Militaris, 8(2).

Škraba, A., Kljaji, M., Knaflič, A., Kofjac, D., \& Podbregar, I. (2007). Development of a human resources transition simulation model in Slovenian armed forces. In J. Sterman (Ed.), Proceedings of the 25th international conference of the system dynamics society (pp. 4480-4490). Boston: System Dynamics Society.

Škulj, D., Vehovar, V., \& Štamfelj, D. (2008). The modelling of manpower by Markov chains-a case study of the Slovenian armed forces. Informatica, 32(3), 289-291.

Smith, M., \& Heinecken, L. (2014). Factors influencing military recruitment in South Africa: The voices of Cape Town high school learners. African Security Review, 23(2), 102-116. https://doi. org/10.1080/10246029.2014.902388.

Smith, A. D., Speten, K., Anglemyer, A., Shingleton, J., \& Alt, J. (2018, June) Predicting US Army first-term attrition after initial entry training (TRADOC Analysis Center TRAC-M-TR-19004). Retrieved February 17, 2020, from https://apps.dtic.mil/dtic/tr/fulltext/u2/1063055.pdf

Steder, F. (2014). Is it possible to increase the share of military women in the Norwegian Armed Forces? International Relations and Diplomacy, 2(5), 293-309. https://doi.org/10.17265/23282134/2014.05.001.

Straver, M., \& Arseneau, L. (2019). Analysis of occupations experiencing shortages: Contribution to North Atlantic Treaty Organization system analysis and studies (SAS)-128 activity (director general military personnel research and analysis reference document DRDC-RDDC-2019D090). Ottawa: Defence Research and Development Canada.

Straver, M., \& Pilat, M. (2017). Employment equity strategic planning model: Overview and results (director general military personnel research and analysis scientific brief DRDC-RDDC-2017B029). Ottawa: Defence Research and Development Canada.

Straver, M., \& Pilat, M. (2018). Analysis of officer population by entry plan (director general military personnel research and analysis scientific report DRDC-RDDC-2018-R224). Ottawa: Defence Research and Development Canada.

Tako, A., \& Robinson, S. (2009). Comparing discrete-event simulation and system dynamics: Users' perceptions. Journal of the Operational Research Society, 60(3), 296-312. https://doi. org/10.1057/palgrave.jors.2602566.

Tustanovski, E., Pejić Bach, M., \& Vrankić, I. (2015). Testing the sustainability of the Croatian military forces: A system dynamics approach. Croatian Operational Research Review, 6(1), 55-70. https://doi.org/10.17535/crorr.2015.0005.

Ueno, R., Boyd, P., \& Calitoiu, D. (2021). Identifying geographical areas using machine learning for enrolling women in the Canadian Armed Forces. In Proceedings of the 10th international conference on operations research and Enterprise systems (ICORES 2021) (pp. 307-316). https://doi.org/10.5220/0010186703070316.

Vaishnavi, V. \& Kuechler, W. (2004). Design science research in information systems. Retrieved February 9, 2021, from http://desrist.org/desrist/article.aspx.

Viljar, V. (2017). Planning and developing the Estonian military forces: Progress, challenges and dilemmas. Tallinn: Estonian Foreign Policy Institute.

Vincent, E., Calitoiu, D., \& Ueno, R. (2018). Personnel attrition rate reporting (director general military personnel research and analysis scientific report DRDC-RDDC-2018-R238). Ottawa: Defence Research and Development Canada.

Wang, J. (2005). A review of operations research applications in workforce planning and potential modelling of military training (Defence Science and Technology Organisation DSTO-TR1688). Retrieved February 18, 2020, from https://apps.dtic.mil/dtic/tr/fulltext/u2/a432084.pdf 
Zais, M., \& Zhang, D. (2016). A Markov chain model of military personnel dynamics. International Journal of Production Research, 54(6), 1863-1885. https://doi.org/10.1080/00207543.2015. 1108533.

\section{Further Reading}

Hill, R. R. (2020). Modern data analytics for the military operational researcher. In N. M. Scala \& J. P. Howard (Eds.), Handbook of military and defense operations research (pp. 3-18). Boca Raton: Taylor \& Francis Group.

Jnitova, V., Elsawah, S., \& Ryan, M. (2017). Review of simulation models in military workforce planning and management context. Journal of Defense Modeling and Simulation, 14(4), 447-463. https://doi.org/10.1177/1548512917704525.

Okazawa, S. (2013). Modelling and simulation for military human resource planning. In J. P. Johnston \& K. Farley (Eds.), Military human resource issues: A multinational view (pp. 19-37). Kingston: Canadian Defence Academy Press.

Vernez, G., Robbert, A., Massey, H., \& Driscoll, K. (2007). Workforce planning and development processes: A practical guide. Santa Monica: RAND Corporation.

Wang, J. (2005). A review of operations research applications in workforce planning and potential modelling of military training (Defence Science and Technology Organisation DSTO-TR1688). Retrieved February 18, 2020, from https://apps.dtic.mil/dtic/tr/fulltext/u2/a432084.pdf

Open Access This chapter is licensed under the terms of the Creative Commons Attribution 4.0 International License (http://creativecommons.org/licenses/by/4.0/), which permits use, sharing, adaptation, distribution and reproduction in any medium or format, as long as you give appropriate credit to the original author(s) and the source, provide a link to the Creative Commons license and indicate if changes were made.

The images or other third party material in this chapter are included in the chapter's Creative Commons license, unless indicated otherwise in a credit line to the material. If material is not included in the chapter's Creative Commons license and your intended use is not permitted by statutory regulation or exceeds the permitted use, you will need to obtain permission directly from the copyright holder.

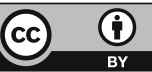

